\section{Monitoring Drug Use in a Community}

SIR: Peveler (Journal, May 1988, 152, 711-712) challenged the conclusions we made regarding the most cost-effective way for a community to monitor its drug problems and emphasised our point that the relationship between drug users and the services in an area is a dynamic one. All Health Districts have been required to monitor the extent of their drug problem, however, and for most, a multi-source enumerative study such as Dr Peveler advocates will be too expensive a procedure.

We helped the South West Regional Health Authority supervise the monitoring of its eleven constituent Health Districts in 1985, in the light of our experience in Bristol and that gained from the North East London Drug Indicators Project (Hartnell, 1985). We saw how it was possible for the members of voluntary and statutory services of the District Drug Advisory Committees to draw together their views of the extent of local drug problems and the attitudes of drug takers towards services. It was apparent that where treatment facilities were lacking, new problem drug users first came to the attention of the police and probation service. Our work throughout the South West confirmed our conclusions from the prospective study in Bristol (Parker et al, 1988), that of all the statutory services who had contact with drug users, it would be most cost-effective to survey five, namely accident and emergency departments, psychiatrists, general practitioners, the Home Office Addicts Index, and probation officers. The results should necessarily be interpreted in the light of the Drug Advisory Committee's knowledge of local circumstances. In fact, the Oxford survey (Peveler et al, 1988) would support these conclusions. Apart from the five we recommended, the only other statutory agencies they included were social services, (which knew of no heroin users), the police, (four convictions only), and the hepatitis returns (12 cases). At least $73 \%$ of the notifications to all agencies surveyed in Oxford would have been detected by concentrating on the five we listed.

It is pertinent to emphasise some of the differences between the Bristol survey and that undertaken in Oxford. The former considered the prevalence of problem drug use associated with illicit drugs or solvents, while in Oxford the case definition was restricted to misuse of heroin or methadone. Dr Peveler, in his letter, discounts the Accident \& Emergency Department as a source of information. In Bristol where our nurse member surveyed all casualty attenders on a regular basis - the three departments were particularly valuable. They provided a vivid picture of young or inexperienced drug users presenting with the adverse effects of drugs, particularly amphetamines, magic mushrooms, LSD, or cannabis, and demonstrated the potential that casualty nurses have for early intervention with this group. One department also knew many chronic opiate addicts who attended for the treatment of their infections, trauma, etc., preferring its anonymity and accessibility to their GP's surgery. Only a handful of heroin users attended the Accident \& Emergency Department to ask for drugs and were refused, as in Oxford (Parker et al, 1986).

The Oxford group invested heavily in field work with drug users. It subsequently combined information from agencies with that from drug users and other sources, while acknowledging the differences in the reliability of the data. It would be of considerable interest to hear how the heroin users, picked up solely by sources listed as "direct admission, other user, relative, other user's suspicion or other's suspicion", differed from those known to agencies. Could this information have been gleaned from key individuals, e.g. from voluntary agencies, youth services or the police? These would be represented on a Drug Advisory Committee and would also have some knowledge about the extent of other illicit drug misuse.

Monitoring problem drug use does not always appear to be a priority for health districts. We conclude that well-planned surveys of the five agencies we listed, interpreted with local knowledge, would provide a cost-effective assessment of the extent and nature of a district's drug problem.

Barrow Hospital

JULIE PARKer Bristol

Royal Hospital for Sick Children

MARTYN J. GaY

St Michael's Hill

Bristol BS2 8BJ

\section{References}

Hartnell, R., Daviand, E., Lewis, R. \& Mitcheson, M. (1985) Drug Problems: Assessing Local Needs. London: Drug Indicators Project, Birkbeck College.

Parker, J., Pool, Y., Rawle, R. \& Gay, M. (1986) Problem Drug Use in Bristol. Report to the DHSS (unpublished). Available from authors.

PARKer, J., POOL, Y., RAWLe, R. \& GAY, M. (1988) British Journal of Psychiatry, 152, 214-221.

Peveler, R. C., Green, R. \& Mandelbrote, B. M. (1988) British Journal of Addiction, 83, 513-518.

Inappropriate Placement of a Patient with Childhood Hypomania in a Mental Handicap Hospital for 51 Years

SIR: We wish to report the case of a patient with hypomania in her childhood, who was admitted 
initially to a psychiatric hospital in 1925 and transferred in 1937 to a mental handicap home, which was later converted to a mental handicap hospital. She is still in hospital and has not been treated for her mood disorder except for two unsuccessful attempts in 1984 and 1988.

Case report: Miss A was initially admitted to a local psychiatric hospital on 9 July 1925, at the age of 15 years, under Section 16 of the Lunacy Act 1890 . According to the notes, on presentation she was "extremely voluble, runs from one subject to another in an excitable and incoherent manner, talks to herself incessantly".

There is no information of her early history. However, her mother stated that from the age of eight she had been over-talkative, highly excitable, anxious, and hysterical. According to her mother, she used to roam the country lanes and would not keep away from men, laughed hysterically and talked all day. Miss A attended school until the age of 14 years and was good at reading and writing. Following admission, she was diagnosed as suffering from dementia praecox. The diagnosis was made on the following observations: "Eccentric, irrational in habits and manner. Chatters incessantly and wanders from one subject to another in conversation. Hears whispering voices and answers them and becomes excited and quarrelsome at times." The notes refer to her intelligence and state that it is much below the average standard for her years. It is difficult to ascertain from the notes how this statement was concluded. Signs and symptoms of either organic brain damage or other metabolic, chromosomal, and genetic disorders were not present.

According to the notes, during her stay in the psychiatric hospital she was treated with 'Mint Menth Pip' occasionally. Over all these years she had not received specific treatment for her mood disorders. Recent attempts to treat her hypomanic episodes with haloperidol and thioridazine were unsuccessful, as she developed idiosyncratic reactions: joint pain, running nose, hyperthermia, anergy, malaise and raised ESR. These symptoms disappeared on the discontinuation of the antipsychotic medication. Psychological testing in July 1973 established a Full Scale IQ of 54 on the Wechsler Adult Intelligence Scale, with a reading age of approximately 13 years. The conclusion was that at her age, after years of institutionalisation, the formal IQ was irrelevant. Her memory is not impaired.

It is rather sad that this lady should have spent all her life in an institution due to a different philosophy of care at that period. In all these years there has been no deterioration in her very pleasant personality. She is still a very friendly and amiable person.

This case highlights the fact that there are still institutions with patients who could have been discharged to the community several years ago, and if proper diagnostic criteria were applied at any given time during these years she would not have been in a mental handicap institution. Therefore, it is important for the future management of such patients not only to use proper diagnostic criteria but also to take an holistic approach when assessing patients.

S. N. FERNANDO JULIE JONES

\section{Risbridge Hospital \\ Kedington \\ Suffolk CB9 7NP}

\section{References}

Paykel, E. S. (ed.) (1982) Handbook of Affective Disorders. Edinburgh: Churchill Livingstone.

Kaplan, H. I. \& SADOCH, B. J. (1988) Synopsis of Psychiatry (5th edn), pp. 631-634. New York: Williams \& Wilkinson.

\section{Hypomania Following Increased Epileptic Activity}

SIR: I report two cases of hypomanic behaviour which followed a rapid increase in the frequency of epileptic discharges in two known temporal lobe epileptics. These findings are in keeping with those of Barczac et al (Journal, January 1988, 152, 137-139), who noted an increase in epileptic discharges to be associated with hypomanic activity.

Case reports: (i) Mr M.N. was admitted via the Emergency Room, following an episode of hypomania. He attempted to donate his body to the State in a police station at $04.00 \mathrm{~h}$. Mental state examination revealed disorientation, flight of ideas, pressure of speech, and paranoid delusions regarding his wife's sexual behaviour. Collateral history from his wife revealed that a change in maintenance therapy had been made, and four generalised seizures had occurred over a period of 3 days. The hypomanic behaviour occurred some 12 hours following the last seizure. Mr M. responded to high dose benzodiazepines administered orally. Carbamazepine therapy has been instituted, and his epilepsy has since remained under control.

(ii) $\mathrm{Mr}$ M.H. was admitted via the Emergency Room following an episode of unusual behaviour in which he proposed to his brother's wife and attempted to pluck hot coals from an open fire. He displayed lability of mood, flights of ideas and pressure of speech at interview, and admitted to being able to see religious images on the curtains of his cubicle, which he found most enthralling. A collateral history from his brother revealed that he had been drinking heavily, and had failed to take his medication for some days. He had developed three generalised seizures in rapid succession, and the episode of hypomania had occurred approximately 8 hours later. $\mathrm{Mr} \mathrm{H}$. responded well to sedation with oral benzodiazepines and returned to his previous anticonvulsant medication. He has remained well for the 5 months since discharge. His alcohol intake has remained high, however.

Both of these patients have been diagnosed as having complex partial seizures from early childhood, one from birth, and the other as a result of a road 